\title{
Research institutes as hybrid organizations: central challenges to their legitimacy
}

\author{
Magnus Gulbrandsen
}

Published online: 11 March 2011

(C) The Author(s) 2011. This article is published with open access at Springerlink.com

\begin{abstract}
Research institutes, here defined as organizations involved in research and development but outside of the higher education sector and often in close cooperation with users, are found in most countries but not very well understood. This paper argues that institutes can be considered "hybrid organizations", caught in between dichotomous cultural spheres with differing values. To retain their hybridity and to survive in the long run, research institutes need to create and sustain organizational legitimacy by establishing congruence with values from these different spheres. The paper discusses how institutes try to establish legitimacy in the science-non-science dimension and the public-private dimension and that these attempts sometimes come into conflict with one another. The framework of the legitimacy of hybrid organizations could constitute a fruitful starting point for a discussion of the future place of research institutes in society.
\end{abstract}

Keywords Hybrid organizations - Boundary organizations - Science policy · Policy cultures

\section{Introduction}

In the last few decades, numerous studies have emerged looking at the role of universities in innovation and in other uses of scientific knowledge in society. The literature tends to highlight the indirect nature of many linkages and the political overemphasis on linear relationships and direct commercialization of academic research (see Mowery and Sampat 2005). In addition to higher education institutions, most countries also have a large number of applied research institutes that are involved both in the production of research and development $(\mathrm{R} \& \mathrm{D})$ and in its use. This happens in a more direct relationship with companies, policy-makers, and other users than what is normally seen in the universities. However, research institutes are significantly less studied and understood than their higher education

\footnotetext{
M. Gulbrandsen ( $\square)$

Centre For Technology, Innovation and Culture, University of Oslo,

PO Box 1108, Blindern, 0317 Oslo, Norway

e-mail: magnus.gulbrandsen@tik.uio.no
} 
counterparts. This paper suggests that these organizations should be considered as hybridsalong two dimensions. They often occupy an intermediary position between public and private organizations when it comes to outputs, governance, ownership, and other issues. In addition, they operate at the boundary of science and non-science, often with close relations in both directions.

Research institutes are important for several reasons. First, they remain a significant part of the world's R\&D organizations, in many national systems equal in R\&D volume to the higher education sector. Second, many of them were set up within policy frameworks that have changed dramatically such as the end of the cold war, increased public skepticism in many countries toward nuclear energy and other technologies, and a now largely abandoned belief in the linear model of innovation. Many institutes have, therefore, come under increasing pressure, and their fundamental legitimacy has been questioned, which makes them an interesting object of study. Third, it may be argued that the global challenges facing the world today require more contact between science and society than ever. If there are limits to the effectiveness of universities' involvement in industry and policy-making, the hybridity that the institutes represent is most likely still needed.

Ideally, the hybrid nature of research institutes can create opportunities for combinations of academic work and practical problem-solving and policy-making (see Stokes 1997), constituting a source of intellectual pluralism and flexibility in public science systems (see Whitley 2003). Stable and well-functioning hybrids may be considered as an institutionalized "Honest Broker of Policy Alternatives" (Pielke 2007) that works in a nonlinear way to expand the range of options available to policy-makers and other users who can benefit from R\&D. Such Honest Brokers are particularly important in contested political issues involving science. But hybridity is difficult to achieve and maintain for research institutes, and there is a constant danger of becoming one of many academic actors or one of many private support companies - in addition to a danger of becoming irrelevant to all but a single user. I argue in this paper that research institutes, therefore, are faced with complicated balancing acts and that maintaining the hybrid position requires a high degree of organizational legitimacy.

I discuss two related questions. First, what are the main characteristics of research institutes when we look at them as hybrid organizations? Second, how do these characteristics give rise to specific challenges to organizational legitimacy? I will use examples mainly from Norway and its many research institutes, based on empirical investigations presented by Gulbrandsen and Nerdrum (2009), Nerdrum and Gulbrandsen (2009) and Gulbrandsen (2008). The underlying aim is to provide an input into the discussion of the relationship between science and society, but with a slightly different starting point than many other empirical and theoretical contributions.

There are 65 research institutes in Norway that receive basic funding from the Research Council of Norway. They are normally categorized into four groups: environmental institutes, social science institutes, agriculture and fishery institutes, and technical/industrial institutes. The latter category has the most members; here, we find among others the SINTEF group with around 2,000 employees. The level of basic funding varies considerably from around $5 \%$ of turnover for some of the technical/industrial institutes to around $50 \%$ for some of the environmental institutes. Their users differ a lot, naturally, from private companies to public agencies in Norway and abroad, and the outputs range from traditional scientific publications to products, testing, policy advice, and more. In total, the research institutes, also including the $R \& D$ units of some public agencies (like the meteorological institute), account for one-fourth of the total Norwegian R\&D expenses. Norway is not unique in this pattern-most European countries have a fairly large number 
of research institutes, and these organizations are also found in North America, Asia, and Australia. For example, Crow and Bozeman (1998) identified more than 16,000 "government laboratories" in the United States alone.

In the following section, I will give a short overview of research institutes and their recent development, followed by a review of two strands of the literature that in different ways have dealt with hybrid organizations. The next section deals with organizational legitimacy, containing a short overview of the concept and the various ways in which organizations strive to establish congruency with the norm and value systems of social environments. The subsequent sections deal with the legitimacy challenges of research institutes related to the public-private dimension and related to the science-society dimension. To guide the analysis, I draw on literature about the "four cultures" surrounding science policy (Elzinga and Jamison 1995). Finally, a short conclusions section aims to give some thoughts to current science policy. A main message is that although hybridity is sought after and held up as an ideal, several policy-related and structural developments in science systems may have made this more difficult to achieve than ever.

\section{Research institutes and their recent development}

Research institutes are organizations involved in research and development activities, but most often not formally in teaching although they may have doctoral students among their staff and have close relations to universities in their vicinity. Ownership, orientation, and financial structure vary between types of institutes and between countries, and the paper investigates organizations that are defined and perceived neither as higher education institutions nor private for-profit companies. There are many names for these such as "public institutes", "government laboratories", and "research and technology organizations" - indicating the obvious heterogeneity among them - and I will use the generic term "research institute" throughout the paper. I will discuss organizations that are involved in the production of scientific and/or technological knowledge, most frequently in partnerships with universities and colleges, and in the active translation of such knowledge into products, processes, policy advice, and other forms of social and political change. They face the challenge of producing knowledge through scientific methods and approaches and in such a manner that users see it as both relevant and as having their best interest in mind.

As mentioned, there are numerous investigations of universities' role in economic, political, and social development but comparatively few of research institutes (notable exceptions include Crow and Bozeman 1998; Larédo and Mustar 2001; Doern and Kinder 2002; Beise and Stahl 1999). One reason could be that these organizations challenge simple dichotomies between "pure" and "applied" science, between public and private sector organizations and between knowledge as "public" (non-appropriable, results from basic research, etc.) and "private" (appropriable, stemming from industrial R\&D). The lack of empirical and theoretical investigations may reflect a wider neglect of forms of hybrid organizations (Miller 2001).

Some research institutes have a long history; if we count astronomical observatories as a form of research institute, their history predates that of universities. In Norway, the country's first organization of this type, responsible for geographical mapping, was established at about the same time as the first national higher education institution. Still, the majority of institutes have been created in the twentieth century and particularly after WW2. 
Three historical origins may be seen (Gulbrandsen 2008). First, many research institutes are related to specific public missions like exploration of the planet and space (geography, geology, etc.), tasks related to nature and natural resources (weather forecasting, agriculture and fishing, environmental mapping, and more), and particular national interests (defense, energy, etc.). Some of them were created as part of a policy long abandoned, like the European "national champions" policy supporting domestic firms in telecommunications, nuclear technology, and other fields with national R\&D institutes. Still, the institutes have most often lived on with a broader customer base and public support for what is seen as national "strategic areas" (Larédo and Mustar 2001, 2004; Larédo 2003) and with higher emphasis on industrial contract research (Beise and Stahl 1999; Larédo and Mustar 2001). Second, some research institutes have been started with explicit goals of industrial and economic growth, oriented at offering R\&D services to industry and at bridging a perceived gap between companies and universities, often in attempts to transfer results from universities into practical use. This model of creating industry-close and industryspecific public R\&D organizations originated in Germany in the late nineteenth century and has been copied by many other countries (Whitley 2002; Beise and Stahl 1999). A subdistinction can be made between institutes oriented at a single industry and large institutes covering a range of industries and technologies. The latter often employ thousands of scientists and engineers with examples such as TNO (The Netherlands), Fraunhofer (Germany), Austrian Competitive Research Centers, VTT (Finland) and SINTEF (Norway). Third, some institutes have been started within research funding agencies to carry out specific tasks, including funding research in universities and developing capabilities similar to mission-oriented and industry-oriented institutes. Examples are CNR in Italy and NRC in Canada, to some extent also CSIC in Spain and CNRS in France.

Some broad trends may be seen for research institutes in the last 2-3 decades. Many of them have been challenged by political developments related to liberalization, marketization, new public management, and more. This has led to a string of reorganizations, mergers, privatizations, and separations of institutes from their original founder (Larédo and Mustar 2001). Also, some institutes have been rooted in specific historical contexts like the cold war, the arms race, and the belief in the linear model of innovation, and they are now faced with completely different political environments with significantly less support. Second, it can be argued that there-partly as a response to the political developments-is a degree of convergence between the three types of institutes outlined in the preceding paragraph. Mission-oriented ones have incorporated goals of industrial development, industry-oriented institutes have assumed broader responsibilities for fundamental R\&D within certain technologies, and agency institutes have become autonomous with similar orientations (Beise and Stahl 1999; Larédo and Mustar 2001; Nerdrum and Gulbrandsen 2009). In many countries, institutes have come strengthened out of discussions about privatization and new missions, offering expertise often in closer relationships to both users and universities (Larédo and Mustar 2004).

But apart from a more general notion of expertise, the theoretical and political basis for research institutes remains somewhat unclear. Some starting points may be found in ideological writings about the need for $R \& D$ organizations that differ from firms and universities (Trist 1972) and empirical investigations revealing how "government research units" differ from both academic and industrial research units along a number of dimensions (Cole 1979). Many university-based scientific disciplines have weak traditions for getting involved in prediction (Sarewitz and Pielke 1999), which could imply a need for other types of R\&D organizations. Policies supporting public-private partnerships-a cornerstone of many institutes' activities—remain important (Audretsch et al. 2002). Still, 
a systematic discussion of the hybrid position may constitute an additional and fruitful line of reasoning for thinking about the rationale for research institutes independent from government agencies, private firms, and higher education institutions.

\section{Hybrid organizations}

There are two research strands that discuss hybrid organizations in a way that is relevant to understanding the role of research institutes. In a tradition from economics and political science, the dichotomy between public and private organizations (and sectors) has been challenged over the last couple of decades. It has been proposed that some organizations occupy a middle position with characteristics that combine those of private companies and government bureaucracies or differ from them altogether. For example, Williamson (1991) looks at how "hybrid organizations" share some attributes with market organizations and other attributes with government hierarchical organizations. Incentive structures are often closer to a market type of governance, while administrative controls are more closely related to hierarchical governance. Ménard (2004) discusses the many varieties of "hybrid organizational arrangements" that combine characteristics of private and public spheres. Here, hybrid organizational forms are tied to situations of mutual dependency between various actors and high degrees of uncertainty. Perry and Rainey (1988) emphasize issues such as ownership, funding, and mode of social control when they discuss a variety of organizational forms that challenge a simple dichotomy between public and private. Rainey and Bozeman (2000) argue that studies of the public-private distinction are often infused with a priori notions about differences and similarities and about whether one type of organization is more efficient etc. than the other.

However, few of the writings in this tradition deal specifically with R\&D organizations; an exception is Rainey and Bozeman (2000) where a comparative study of industrial and government $\mathrm{R} \& \mathrm{D}$ units is used to nuance the public-private distinction. Most of the literature deals with hybrid arrangements such as alliances between companies, collective trademarks, and franchising, which seems somewhat remote to a discussion of research institutes. The general message is still that the intermediary position offers challenges in a world of a dichotomous either-or, where there may be pressures to organize certain activities either as markets or as government hierarchies, two ideal types that differ a lot in governance and cultural aspects (Karré et al. 2008). Hybrid organizational forms are often unstable, with many forces pushing toward change (Ménard 2004). Since R\&D funding of a certain type carries with it specific demands and influences (Rainey and Bozeman 2000), hybrid organizations with multiple funding sources and neither strong roots in a company's operations nor the academic community, may be stretched in different and seemingly incommensurable directions.

In a tradition based in studies of science, technology, and innovation, the most frequent term has been that of the "boundary organization" (Guston 1999). The starting point is that there is "an unyielding tension between basic and applied research, and between the empirical and theoretical aspects of inquiry" (Gieryn 1983:787), meaning that the boundary between science and non-science is blurred and has to be actively constructed. This "strategic demarcation between political and scientific tasks" (Guston 2001) is typical of the hybrid organizations found at the interface between science and other parts of society. It can be assumed that all boundary organizations are hybrids, although not all research institutes may relevantly be seen as boundary organizations. 
Some authors speak directly of hybrid organizations. Lynn et al. (1996) describes how intermediary organizations can play a key role in the commercialization of new technologies in "innovation communities" which are often organized around a single technology. Fransman (2001) discusses the role of "hybrid institutions" in economic, technological, and scientific development with the specific case of the cloned sheep Dolly and the role of the Roslin Institute in Edinburgh together with PPL Therapeutics and Edinburgh University. The term "hybrid institution" here refers to a combination of organizations with a government research institute at the core, together with its spin-off companies and neighbor university.

Just as Guston (2001) argues, research institutes often create spaces with participation of actors from "both sides" of a boundary but also employ their own professionals who may serve both a mediating and independent role: "The boundary organization thus gives both the producers and the consumers of research an opportunity to construct the boundary between their enterprises in a way favorable to their own perspectives" (p. 405). For research institutes, this means that they often present a face of $R \& D$ to users in industry, policy, and elsewhere and at the same time, interpret trends and demands in society in interactions with representatives of academic institutions. Two examples from Norway indicate the complex environment in which institutes operate. The Defense Research Institute was historically set up not only to cater for the needs of the Norwegian military and defense policy, but also to help build national and partly civilian industries in fields such as marine electronics, and to coordinate huge technological projects involving multiple universities, firms, institutes, and user communities. It was referred to as "the small institute for large projects", not dissimilar to (D)ARPA in the US Careful balancing acts, and strong political support was needed to ensure the success of multi-billion dollar endeavors like the Penguin missile project. Despite policy changes after the end of the cold war, the institute largely retains this hybrid role, and Norway remains among the world's top ten weapons exporting nations with the institute as one important coordinator. The Telecommunications Institute had a similar function in the R\&D system from the 1960s, working with universities, national and foreign firms, and several policy agencies and ministries. It played a pivotal role in developing the GSM mobile phone technology, a process which also revealed the legitimacy challenges for a national organization attempting to work with firms from different countries. Following the liberalization in the industry in the early 1990s, the institute was dissolved, its R\&D units becoming parts of the largest telephone company in Norway.

There are also other examples of hybrid organizations in the science and innovation studies literature. Etzkowitz and Leydesdorff (2000) discuss hybrid organizations like science parks, incubators and technology transfer offices, arguing that they can play a more important role than more "static" industrial and public laboratories. Technology transfer offices are also discussed by some authors in the language of hybrids and boundary organizations (Owen-Smith 2003; Guston 1999). Hagedoorn et al. (2000) categorize research partnerships between different sectors as a hybrid form of organization oriented at both the production and dissemination of technical knowledge.

All these investigations can be helpful for understanding research institutes, not least the analytical language of being hybrid and being on the boundaries between different worlds. Research institutes may even offer a good insight into the challenges of hybridity and boundary organizations, since they for the main part have been around for many more years than most technology transfer offices and the like. This longer history means that research institutes have enjoyed greater stability and legitimacy and may offer a repository of experiences in that respect. 
It is claimed that the number of hybrid organizations more generally is increasing due to a number of societal changes like the erosion of authority of public organizations, autonomization of public services, and introduction of market forces (Karré et al. 2008). Although much of the literature deals with the many challenges of hybrid organizations, an underlying message is nevertheless that they can be a solution to complex dilemmas in modern societies such as pooling of expertise, collective decision-making, and interpretation between different social groups (ibid.). Hybrid R\&D organizations can be seen as playing an important role in reconciling supply and demand in science (Sarewitz and Pielke 2007) or facilitating the way practical and commercial development projects give rise to new scientific puzzles and breakthroughs (Fransman 2001).

It should be added that the categories of "public", "private", "science", and "nonscience" are by no means clear-cut and static. As mentioned, Gieryn (1983) contains a fundamental critique of the view that there is any "natural" boundary between science and non-science and Rainey and Bozeman (2000) show how many investigations of differences between public and private organizations are infused with ideological starting points. The terms themselves can furthermore be moving targets. For example, the categories of private and public may become even more blurred as social control by government authority in many cases has been switched toward market exchange mechanisms (see Perry and Rainey 1988).

Finally, these two dimensions of hybridity (public-private and science-non-science) are not independent, because many scientific institutions are also public in most countries. Many users of science are also public, ranging from policymakers to technology users in public service organizations, i.e. the dimensions intersect in complex manners. It is still analytically relevant to distinguish between the two dimensions of hybridity because they give rise to different types of challenges to legitimacy.

\section{Organizational legitimacy}

As Dowling and Pfeffer (1975:131) argue, "Legitimacy provides a linkage between the organizational and societal level of analysis", which means that the term is very relevant in a discussion of the role of science and science-producing organizations in policy-making. Organizations need legitimacy to be able to survive. Without it, they will suffer different types of sanctions from other actors (Dowling and Pfeffer 1975), and the lack of it could threaten the survival of the organization (Singh et al. 1986). Guston (2001) argues that boundary organizations provide stability between science and non-science "only through the consent of actors on both sides of the boundary" (p. 400), which also points at legitimacy.

Legitimacy refers to "congruence between the social values associated with or implied by their activities and the norms of acceptable behavior in the larger social system of which they are a part" (Dowling and Pfeffer 1975:122). In other words, when a disparity exists between these systems of norms and values, a threat to organizational legitimacy may be seen. It is argued that the disparity need not be "actual" but perceived as a potential problem. The point to make regarding hybrid organizations is that these are not only threatened by a disparity between an internal value system and a singular external onethey are challenged by the fact that their dual linkages create situations with disparities with multiple social systems, often with conflicting values. There is more than one "superordinate system". A related point is that value systems are dynamic (ibid. p. 126), and hybrid organizations need to pay attention to several different changing value systems 
simultaneously. Norwegian petroleum research institutes are expected to offer useful knowledge to oil companies, to policy-makers interested in exploiting the country's resources in a sustainable manner with no preference for specific companies, and to a general public which may perceive tensions between oil drilling and, for example, protecting the natural environment.

Dowling and Pfeffer (1975:133) hypothesize that legitimacy is particularly important to highly visible organizations and large organizations. This is not necessarily relevant to all research institutes, some of which may have gone about their mission-oriented tasks outside of the public spotlight. However, with ever more political debate surrounding topics like energy, environment, and economic growth-issues in the very heartland of research institute activities in many countries - it can be assumed that their visibility has and will increase and that their legitimacy can be questioned. And as mentioned above, many of the world's mission-oriented and industry-oriented research institutes are large, like the German Fraunhofer conglomerate with more than 17,000 staff.

There are many different answers to the challenge of gaining and keeping legitimacy, but two main strategies are mentioned in the literature (Dowling and Pfeffer 1975; Singh et al. 1986). The first one is to change internal activities and goals to conform to external value systems, similar to the process of isomorphism in institutional theory (DiMaggio and Powell 1983). In other words, organizations mimic characteristics of and changes in the environment. It is probably no coincidence that research institutes very often have career ladders closely modeled after the ones found in universities, signifying the importance of expertise and seniority and serious evaluation criteria for each step toward the "full professor" category.

The second strategy to gain and keep legitimacy is more externally oriented whereby the organization aims to become identified with symbols, actors, etc. which already enjoy a position of strong legitimacy (Singh et al. 1986). Pfeffer and Dowling (1975) also mention how some organizations try to influence the values of their surroundings. In Norway, research institutes have for a long time argued for the value of long-term applied research activities, and more recently framed this as promoting "use-inspired basic research" (Stokes 1997) because this is how many of them perceive their own activities. This switch is probably related to a change in policy communities valuing basic research and innovation and placing less emphasis on "applied research". Although Stokes' term is initially more oriented at understanding varieties of academic research, the applied institutes invoke the hybridity of the notion in an attempt to elaborate the legitimacy of their own position in the system - and thereby secure what they see as a sufficient level of basic funding.

\section{Legitimacy challenges for research institutes}

To elaborate a bit more on the external norms and values facing these organizations, it can be helpful to draw on a perspective about cultures surrounding science policy (Elzinga and Jamison 1995), which has been fruitfully applied to discussions about evaluations of science and technology (Kallerud 2002). Elzinga and Jamison (1995) claim that science policy is a staging ground for four competing cultures: the academic culture, the industrial culture, the bureaucratic culture, and the civil culture. Each is based on sets of norms and values that most often differ from the other ones, and the institutions, organizations, and development processes of science policy are continually influenced by the struggle between these four cultures. In such a complex setting, legitimacy in the sense of creating congruence between internal and external norms and values is certainly a daunting task. 
The academic culture emphasizes autonomy and academic freedom and upholds an image of "pure", "unrestricted", and "curiosity-driven" research as an ideal and often as the foundation for all types of R\&D. This set of values is well established within universities, many research funding agencies, and some other actors. The industrial culture, typically found within firms but also in public agencies set up to support economic and industrial growth, emphasizes values like competitive advantage and innovation. R\&D is typically seen as a tool to promote these values, and it should consequently be based on articulations of demands among users who strive to become innovative and competitive. Bureaucratic culture is founded on values related to orderly rules, rationality, and planning. This implies that R\&D is largely viewed in an instrumental light, both as a tool to create achievable goals and efficient rules and as a source of authority for planners and regulators. Civil society culture is more difficult to characterize, but its influence is often most explicitly seen in various protest movements against the values of some (or all) of the other three cultures (Kallerud 2002). Environmental perspectives, animal rights, and democratic participation in the formulation and execution of $R \& D$ are some of the issues that have been raised.

This is, of course, an oversimplified picture, and the cultures are neither as homogenous nor as distinct as presented here. The framework nevertheless serves well as a starting point for analyzing the doubly dual nature of research institutes. The four cultures are easily tied to the two dimensions of hybridity presented above, and I have depicted this in Fig. 1 where I have referred to the endpoints of the hybrid dimensions as "spheres". Here, I have also named what I see as the most important challenges to legitimacy related to the extremes of each of the two dimensions or to each of the four cultures.

It should be emphasized that legitimacy is first and foremost important to hybrid organizations that want to remain in the hybrid position, in Guston's (2001) words to achieve "stability" and "balance" between dependence and independence. With the

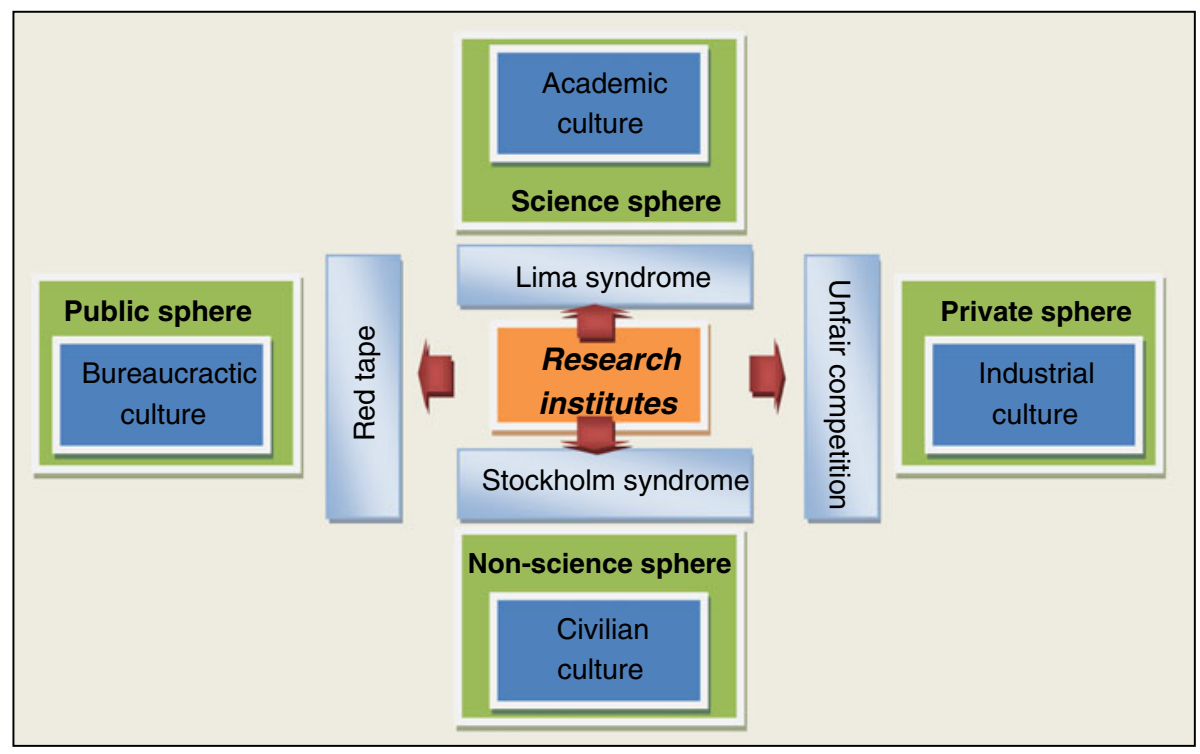

Fig. 1 The two hybrid dimensions, the four science policy cultures, and the challenges to legitimacy for hybrid organizations in this landscape 
pressures from value disparities, goal conflicts, and more, there is a risk that the hybrid research organizations gradually come to belong to one of the cultures, turning into a more traditional academic organization or a regular private for-profit company offering R\&Dbased products and services. Another challenge is related to remaining visible and relevant. A low degree of legitimacy may mean that the hybrid organization becomes liminal, i.e. in an in-between powerless position with little influence, perhaps, apart from with the government agency, industry organization, or other actor that emerges as the main user or founder of the hybrid.

The science-non-science dimension

There are two very similar challenges in maintaining organizational legitimacy for research institutes related to the science-non-science dimension. I have called these the Stockholm Syndrome and the Lima Syndrome, and both are related to the drift of epistemic criteria (Elzinga 1985). The terms have originally been used to describe kidnapping incidents or hostage situations where hostages develop signs of loyalty to their hostage takers (Stockholm Syndrome) or vice versa, that the kidnappers develop sympathy toward their hostages (Lima Syndrome) - both terms are based on actual hostage situations in the two cities from which they draw their names. These terms may not be as far fetched as they seem-other authors have also pointed at hybrid organizations constituting a "hostage situation" through which different partners are forcibly committed to a common cause (Hagedoorn et al. 2000:571).

Seen from the science sphere, research institutes' close relationship with users comes into conflict with core values of "pure research" and scientific autonomy. In this light, research institutes become hostages of their clients, and like the Stockholm Syndrome hostages, they develop sympathy for the clients' perspectives. This consequently leads to drift of epistemic criteria with a normative shift in assessments of quality of R\&D from the researchers themselves to external economic and political forces (see Elzinga 1985). This concern is expressed in different ways, from accounts in concrete cases that research institutes have failed to be critical (enough) toward their clients, to more ideological statements that external funding and close user relationships make the R\&D "tainted" and of less value. The completely opposite concern has been raised as well-users and other actors worry that research institutes become too preoccupied with contributing to academic science in a way that undermines their usefulness to society, or the legitimacy derived from users believing the institutes have their best interest in mind. I have called this the Lima Syndrome, although it might just as well be viewed as another variety of the Stockholm Syndrome. It is similar to a moral hazard situation in principal-agent theory (see Guston 1999, 2001). In Norway, a recent performance-based funding system for the research institutes, emphasizing scientific publishing, competitive research funding, and traditional scientific networking led to discussions along these lines.

Most research institutes have experienced these tensions and challenges. Although there might not be a widely shared belief (anymore) that working commercially with users and being involved in academic science for the benefit of society are mutually exclusive, practical situations still arise when hybrid organizations get caught in the middle between conflicting value systems.

The answers to the Stockholm Syndrome challenge are often internal, i.e. the research institutes try to adopt their processes and modes of operation to the academic value system. As mentioned above, research institutes often mimic academic career systems despite operating in very different markets and disciplinary fields. They are more and more 
involved in traditional academic publishing, and they also increasingly emphasize R\&D excellence and try to develop unique expertise in select fields. Here, the institutes take the language of academic excellence and apply it to cross-disciplinary and user-oriented areas. Some research institutes can-more effectively than universities who are often obliged to cover broader teaching areas - thus act as a concentration of R\&D resources in national systems. External strategies for gaining legitimacy are formal linkages to leading research universities and adjunct positions where university professors have a part-time position in the institute or vice versa. This of course also serves to uphold universities' legitimacy in a time when higher education institutions are challenged by expectations of direct contributions to utility value in industry and society at large.

Internal answers to the Lima Syndrome challenge of perceived academic drift are often related to modes of working, being engaged in various informal communication processes and agreeing to various demands in projects. Research institutes, much more than universities, will accept secrecy agreements when their clients demand it. However, it can be argued that the main strategies for handling Lima Syndrome legitimacy issues are external, for example by co-opting lead users as board members or members of steering committees and other groups. Although adjunct positions between research institutes and users are uncommon, a strong sign of legitimacy is the turnover of personnel from the institutes. In Norway, most research institutes have a remarkably annual high share of their staff leaving to find work with companies or other clients (see Nerdrum and Gulbrandsen 2009). Some of the technical/industrial institutes have an annual turnover of more than $15 \%$, which is unusually high for public R\&D organizations in the country. This is a clear signal that they retain their hybridity, as the similar turnover of personnel from universities is negligible. The external co-opting strategies of adjunct positions, board membership, and turnover of personnel are useful to achieve efficient commercialization of $R \& D$ and infuse basic research with challenges from technological practice (like in the Dolly case, see Fransman 2001). In addition, they are most likely relevant for "managing the boundary" (Guston 1999), by disseminating an understanding of the nuances of the particular work and orientation of different organizations throughout the research system. Through this, a division of labor is constructed and preserved, which also helps stabilize the boundary and maintain hybridity.

The public-private dimension

The public/private distinction can be seen as directly relevant to research institutes, because their status is often not very clear. For example, most research institutes in Europe are defined as "public" in national R\&D statistics, but in the OECD R\&D statistics many of them (typically the technical/industrial ones in Norway) are classified as "private". The distinction is very important because being "private" or "public" yields different financial and regulatory obligations and advantages.

The main legitimacy challenge for hybrid organizations in this respect is to counter allegations of "unfair competition" which come in many forms. The most common is a claim that research institutes' activities do not differ in any significant way from those of (some) private firms involved in consultancy and R\&D services, which then creates a situation of unfair competition if institutes receive benefits like a public core funding. This claim can come from a variety of sources; in Norway, the national tax authorities have started demanding that institutes start paying taxes like other companies based on a perception that the distinction is negligible. Private firms complain that institutes "keep the meter running" even during informal contact. Seen from the private sector, legitimacy is 
challenged when competing or partly competing organizations do not mutually recognize and accept each other's spheres of activity (Dowling and Pfeffer 1975:125). Normally, there is a differentiation of functions in a research system between private firms, research institutes, and academic institutions. But if private firms increasingly operate within the same scientific and technological areas as research institutes (or vice versa), legitimacy is threatened because the differentiation has changed. In Norway, there have been some complains that research institutes out-compete academic spin-off companies, which tend to establish themselves within technological areas that are already covered by institutes.

Another complication related to competition arises when clients want to see research institutes as merely profit-seeking actors in a market for R\&D. Some industry representatives in Norway have expressed concern about the blurring boundaries between institutes and universities (cf. Gulbrandsen and Larsen 2000). The companies want to treat the research institutes "just as any other supplier", while they want to have a more "long-term and philanthropic" approach toward the universities, but they become confused with the large number of people holding positions in both types of organizations. Thus, one of the common responses to the legitimacy challenges of the science-non-science dimension may make it more difficult for institutes to operate efficiently in R\&D markets.

A very different concern is sometimes raised that hybrid organizations' market activities oust their public activities or that they neglect their tasks that do not generate income (see Karré et al. 2008). If they define themselves as partly public and derive some benefits like core funding or no income tax, some would claim that they are then also obliged to play a larger societal role than simply answering clients' questions. Such concerns are often expressed by political actors like environmental groups, which for instance argue how institutes should "serve Norway rather than the large domestic oil companies". This legitimacy challenge is, therefore, at the intersection between the industrial culture and the civilian culture. Again, the problem for the hybrid organization is a double one: co-opting a large an important user to demonstrate that it manages the science-non-science balance may create an image that the organization serves none other than this user, i.e. undermining the stability in the public-private dimension if this is partly based on a collective role.

Finally, when hybrid organizations are viewed from the private side, they may be challenged by traditional worries about the inefficiencies and rigidities of public organizations. This is referred to as Red Tape in Fig. 1. Research institutes may be accused of being "bureaucratic", inflexible or tied to goals and procedures of an age long past. When policies change some institutes are dissolved, like the whaling research institute around 80 years ago in Norway (although the institute for herring oil and flour from the 1930s still exists), but most often they strive to adapt their activities to new situations. When the Norwegian Energy Research Institute in the early 1970s was faced with a political environment that would never accept commercial nuclear power-its key technology and activity - it had to find new domains (see Gulbrandsen and Nerdrum 2009). Expertise related to corrosion and fluid mechanics could be applied in the fast-growing oil and gas industry in the North Sea. To some extent, this challenge of a discrepancy between historical origins and present context was the first challenge dealt with through the reorganization of Europe's research institutes reported in Larédo and Mustar (2001).

A central response to the legitimacy challenges of the public-private dimension is to establish a form of ownership that clearly signals the hybrid position. For most research institutes in Norway, this means a private non-profit foundation model or a stock company model where the shares are owned by universities and large firms and with rules stating that the owners are not allowed dividends. Another response is to split the activities of the research institutes into different organizations. Several of the larger technological research 
institutes in Europe have created separate organizations to create spin-off companies for closer-to-market activities that cannot be justified by the overall umbrella of research and development. SINTEF has its own commercialization unit which is run in a similar way as a university technology transfer office. Even hybrid organizations may need additional boundary organizations. A somewhat similar process was seen in the cloned sheep Dolly case (Fransman 2001). Another typical solution is to maintain a pricing of R\&D services that falls somewhere in between consultancy companies and universities involved in contract research. Like the science-non-science dimension, co-optation of key external actors through board membership and other formal arrangements is also an important strategy to maintain legitimacy in the public-private dimension. Only through a clearly signaled middle position can this be upheld. The selection of a leader for the institute is probably important for all challenges, as legitimation often happens at the institutional level of formal organizations (Dowling and Pfeffer 1975).

\section{Conclusion}

Above, I have argued that research institutes-organizations outside of higher education that are involved in the production and dissemination/use of R\&D—can be considered as hybrids along two dimensions. First, they occupy a middle point between science and nonscience/society, and second, they most often have characteristics both of private firms and government bureaucracies. These hybrid positions create challenges to the institutes' legitimacy because there are real and potential disparities between external values and norms and those found within the research institutes. The institutes have to balance norms and values stemming from the four different extremes of the hybrid dimensions, envisaged as the academic, industrial, bureaucratic, and civil cultures (Elzinga and Jamison 1995).

In the science-non-science dimension, reflecting tensions primarily between academic and civilian cultures (but to some extent between academic values and those of the other cultural spheres), I have pointed at dilemmas which I have called the "Stockholm Syndrome" and the "Lima Syndrome". The first refers to the challenge that research institutes may be or perceived to be "in the pockets" of their users, which means they are unable to offer R\&D services that correspond to ideals of objectivity, criticism, balance, independence, etc. Like the hostages in the Stockholm Syndrome, the institutes develop sympathies with the "hostage takers" and their perspectives. The Lima Syndrome denotes the opposite tendency, and I have used it to describe the challenge of actual or perceived academic drift which makes central actors believe that the research institutes risk becoming less useful and/or that the more practically oriented R\&D activities are viewed as low status tasks. Typical legitimacy-increasing responses to the Stockholm Syndrome are internal, like active scientific publishing and adopting university-like career ladders and promotion criteria. Responses to the Lima Syndrome are often external, like the involvement of users in boards, steering committees, and other formalized tasks, as well as ensuring a fairly high degree of turnover from the institute to the rest of society. Given a research system that is ever more collaborative-measured by, for example, joint projects and joint publications - it is unlikely that collaboration alone will yield enough legitimacy for research institutes.

Dilemmas related to "unfair competition" are the most important ones in the publicprivate dimension, based on tensions between industrial and bureaucratic (and to some extent civilian) cultural values. If research institutes compete in the same market as private firms, while at the same time enjoy benefits of the hybrid position like public basic R\&D 
funding, reduced taxes, and access to certain funding arenas closed for for-profit organizations, they will most likely be faced with this dilemma. It could be exacerbated through an increasing number of sophisticated R\&D-based companies, for example academic spinoff companies. Research institutes with an identity closer to the public sector can also be met with fairly traditional "red tape" accusations, i.e. excessive conformity to rules and regulations, inefficient operations, and more. The most common response to both unfair competition and red tape is to establish a type of organization and ownership that clearly signals the intermediary position such as a private non-profit foundation or stock company with public shareholders and no annual dividends. Aligning internal activities to the organization type is probably also necessary to create legitimacy for the hybrid role, i.e. finding a middle road in decisions about prices, organizational design, etc.

This fairly simple framework has served to highlight how a hybrid position between different cultures or spheres may be legitimated and strengthened. It has also revealed how the two dimensions of hybridity and some of the solutions to the legitimacy challenges may conflict with one another. Attempts to balance the science-non-science dimension could, for example, make it harder to find legitimacy for the middle position between public and private organizations. Of course, research institutes are very heterogenous, which means that different institutes might experience one of the hybrid dimensions stronger than the other one. In Norway, it is likely that the social science institutes struggle more to find the well-functioning hybrid position between science and non-science, caught between university professors with ideals of critically distanced research and users worried about academic isolation. Technical/industrial institutes, on the other hand, need to have a close relationship to their users in private firms, in a manner probably not very different from the firms' other suppliers and partners. Yet these institutes also need to retain some characteristics of public service organizations to keep privileges like certain types of research funding and beneficial tax regimes.

As shown by the framework in Fig. 1, the hybrid position may be difficult to defend, and it is not based on a simple and well-established set of values like the traditional academic values. Institutes are under pressure from at least two directions: universities seek ever more external funding, and $R \& D$ competences and intensity in industry are increasing. The traditional hybrid role of research institutes is therefore now played by a larger number of actors. But although university-industry relations and commercialization of research are promoted in many countries' science policies, the rhetoric is nevertheless often dichotomous where the two main goals are excellence in basic science and contributions to innovation and economic growth. The type of hybridity represented by the research institutes could, therefore, become even more difficult to uphold in the current situation, because they neither represent academic excellence in a narrow sense nor direct economic competitiveness.

Some countries, like Denmark, have opted to merge all research institutes into higher education institutions, and closer collaboration seems to be the norm all over the world. To some extent, this changes the universities into hybrid institutions, caught between concrete national needs and global science. Although some universities may be comfortable in such a position - they have arguably been there all along - many of them are firmly rooted in the academic culture and do not have a self-image as hybrids that are highly reactive to external needs. If the activities of research institutes still have a distinct role to play in systems of innovation and research, they will probably need a clearer policy justification. To think systematically about hybrid dimensions and solutions to the legitimacy challenges, they entail could provide a fruitful starting point in this respect. 
Open Access This article is distributed under the terms of the Creative Commons Attribution Noncommercial License which permits any noncommercial use, distribution, and reproduction in any medium, provided the original author(s) and source are credited.

\section{References}

Audretsch, D. B., et al. (2002). The economics of science and technology. Journal of Technology Transfer, 27, 155-203.

Beise, M., \& Stahl, H. (1999). Public research and industrial innovations in Germany. Research Policy, 28(4), 397-422.

Cole, G. A. (1979). Classifying research units by patterns of performance and influence: A typology of the Round 1 data. In F. M. Andrews (Ed.), Scientific productivity the effectiveness of research groups in six countries (pp. 353-404). Cambridge/Paris: Cambridge University Press/Unesco.

Crow, M. M., \& Bozeman, B. (1998). Limited by design. R\&D laboratories in the U.S. national innovation system. New York, NY: Columbia University Press.

DiMaggio, P. J., \& Powell, W. W. (1983). The iron cage revisited: Institutional isomorphism and collective rationality in organizational fields. American Sociological Review, 48, 147-160.

Doern, G. B., \& Kinder, J. S. (2002). Strategic science in the public interest: Canadas government laboratories and science-based agencies. Toronto: University of Toronto Press.

Dowling, J., \& Pfeffer, J. (1975). Organizational legitimacy: Social values and organizational behavior. Pacific Sociological Review, 18, 122-136.

Elzinga, A. (1985). Research, bureaucracy and the drift of epistemic criteria. In B. Wittrock \& A. Elzinga (Eds.), The university research system. The public policies of the home of scientists. Stockholm: Almqvist \& Wicksell International.

Elzinga, A., \& Jamison, A. (1995). Changing policy agendas in science and technology. In S. Jasanoff, et al. (Eds.), Handbook of science and technology studies. Thousand Oaks, CA: Sage Publications.

Etzkowitz, H., \& Leydesdorff, L. (2000). The dynamics of innovation: From national systems and 'Mode 2' to a Triple Helix of university-industry-government relations. Research Policy, 29, 109-123.

Fransman, M. (2001). Designing Dolly: Interactions between economics, technology and science and the evolution of hybrid institutions. Research Policy, 30, 263-273.

Gieryn, T. F. (1983). Boundary work and the demarcation of science from non-science: Strains and interests in professional ideologies of scientists. American Sociological Review, 48, 781-795.

Gulbrandsen, M. (2008). The co-evolution of research institutes with universities and user needs: A historical perspective. In Eli. Moen (Ed.), Science and society relationships in the age of globalization: Past reforms and future challenges (pp. 188-213). Oslo: Research Council of Norway.

Gulbrandsen, M., \& Larsen, I. M. (2000). Forholdet mellom naringslivet og UoH-sektoren: et krevende mangfold. Oslo: NIFU, Report 7/2000.

Gulbrandsen, M., \& Nerdrum, L. (2009). Public sector research and industrial innovation in Norway: A historical perspective. In J. Fagerberg, D. C. Mowery, \& B. Verspagen (Eds.), Innovation, pathdependency, and policy: The Norwegian case (pp. 61-88). Oxford: Oxford University Press.

Guston, D. H. (1999). Stabilizing the boundary between US politics and science: The role of the office of technology transfer as a boundary organization. Social Studies of Science, 29, 87-111.

Guston, D. H. (2001). Boundary organizations in environmental policy and science: An introduction. Science, Technology \& Human Values, 26, 399-408.

Hagedoorn, J., Link, A. N., \& Vonortas, N. S. (2000). Research partnerships. Research Policy, 29, 567-586.

Kallerud, E. (2002). Vitenskap, teknologi og makt-fire perspektiver på evaluering. In B. Stensaker (Ed.), Kunnskaps- og teknologivurdering. Perspektiver, metoder og refleksjoner (pp. 31-54). Oslo: Cappelen akademisk forlag.

Karré, P. M., van der Steen, M., \& van Twist, M. (2008). On the road to total hybridisation? Eroding dichotomies in public service provision. Paper presented at the workshop Innovation and change through alliances in the service, public and education sectors, Suffolk University, Boston MA, 25-27 June 2008.

Larédo, P. (2003). Six major challenges facing public intervention in higher education, science, technology and innovation. Science and Public Policy, 32.

Larédo, P., \& Mustar, P. (Eds.). (2001). Research and innovation policies in the new global economy. An international comparative analysis. Cheltenham: Edward Elgar.

Larédo, P., \& Mustar, P. (2004). Public-sector research: A growing role in innovation systems. Minerva, 42, 11-27. 
Lynn, L. H., Mohan Reddy, N., \& Aram, J. D. (1996). Linking technology and institutions: The innovation community framework. Research Policy, 25, 91-106.

Ménard, C. (2004). The economics of hybrid organizations. Journal of Institutional and Theoretical Economics, 160, 345-376.

Miller, C. (2001). Hybrid management: Boundary organizations, science policy, and environmental governance in the climate regime. Science, Technology \& Human Values, 26, 478-500.

Mowery, D. C., \& Sampat, B. N. (2005). Universities in national innovation systems. In J. Fagerberg, D. C. Mowery, \& R. R. Nelson (Eds.), The oxford handbook of innovation (pp. 209-239). Oxford: Oxford University Press.

Nerdrum, L., \& Gulbrandsen, M. (2009). The technical-industrial research institutes in the Norwegian innovation system. In J. Fagerberg, D. C. Mowery, \& B. Verspagen (Eds.), Innovation, path-dependency, and policy: The Norwegian case (pp. 327-348). Oxford: Oxford University Press.

Owen-Smith, J. (2003). From separate systems to a hybrid order: Accumulative advantage across public and private science at research one universities. Research Policy, 32, 1081-1104.

Perry, J. L., \& Rainey, H. G. (1988). The public-private distinction in organization theory: A critique and research strategy. Academy of Management Review, 13, 182-201.

Pielke, R. A., Jr. (2007). The honest broker: Making sense of science in policy and politics. Cambridge: Cambridge University Press.

Rainey, H. G., \& Bozeman, B. (2000). Comparing public and private organizations: Empirical research and the power of the a priori. Journal of Public Administration Research and Theory, 10, 447-469.

Sarewitz, D., \& Pielke, R. A., Jr. (1999). Prediction in science and policy. Technology in Society, 21, 121-133.

Sarewitz, D., \& Pielke, R. A., Jr. (2007). The neglected heart of science policy: Reconciling supply of and demand for science. Environmental Science and Policy, 10, 5-16.

Singh, J. V., Tucker, D. J., \& House, R. J. (1986). Organizational legitimacy and the liability of newness. Administrative Science Quarterly, 31, 171-193.

Stokes, D. E. (1997). Pasteur's quadrant: Basic science and technological innovation. Washington, DC: Brookings Institution Press.

Trist, E. (1972). Types of output mix of research organizations and their complementarity. In A. B. Cherns (Ed.), Social science and government: Politics and problems (pp. 101-138). London: Tavistock Publications.

Whitley, R. (2002). Developing innovative competences: The role of institutional frameworks. Industrial and Corporate Change, 11, 497-528.

Whitley, R. (2003). Competition and pluralism in the public sciences: The impact of institutional frameworks on the organisation of academic science. Research Policy, 32, 1015-1029.

Williamson, O. E. (1991). Comparative economic organization: The analysis of discrete structural alternatives. Administrative Science Quarterly, 36, 269-296. 